\title{
Proving their love: Violence and gender norms in descriptions of relationships among rural Mexican adolescents
}

\author{
Heidi Adams Rueda \\ University of Texas at San Antonio \\ Steven Hoffman \\ Brigham Young University - Provo, steven_hoffman@byu.edu \\ Kaitlin Grytza \\ University of Texas at San Antonio
}

Follow this and additional works at: https://scholarsarchive.byu.edu/facpub

Part of the Social Work Commons

\section{Original Publication Citation}

Hoffman, S., Rueda, H. A., \& *Beasley, L (2019). Youth perspectives of health care in Central Mexico: An application of Massey's critical health framework. International Journal of Environmental Research and Public Health, 16, 896-909.

\section{BYU ScholarsArchive Citation}

Rueda, Heidi Adams; Hoffman, Steven; and Grytza, Kaitlin, "Proving their love: Violence and gender norms in descriptions of relationships among rural Mexican adolescents" (2019). Faculty Publications. 4115. https://scholarsarchive.byu.edu/facpub/4115 accepted for inclusion in Faculty Publications by an authorized administrator of BYU ScholarsArchive. For more information, please contact ellen_amatangelo@byu.edu. 


\title{
Proving their love: Violence and gender norms in descriptions of relationships among rural Mexican adolescents
}

\author{
Heidi Adams Rueda ${ }^{\mathrm{a}, *}$, Steven Hoffman ${ }^{\mathrm{b}}$, Kaitlin Grytza ${ }^{\mathrm{a}}$ \\ ${ }^{a}$ Department of Social Work, The University of Texas at San Antonio, 501 W. César E. Chávez Blvd, San Antonio, TX 78207, United States of America \\ ${ }^{\mathrm{b}}$ School of Social Work, Brigham Young University, 2167 JSFB, Provo, UT 84602, United States of America
}

\section{A R T I C L E I N F O}

\section{Keywords:}

Adolescent dating violence

Sexual assault

Latino

Qualitative

Mixed methods

Rural

\begin{abstract}
A B S T R A C T
Mexican youth from impoverished areas are at increased risk for experiencing relationship violence. Research in the United States has suggested that perpetration may be contextualized by culturally-influenced gender values, specifically performance of negative aspects of male masculinity (i.e., machismo) and its female counterpart (i.e., marianismo). This study utilized focus group methods to explore how middle school adolescents $(N=98)$ from a rural area of Central Mexico differentiate between healthy and unhealthy dating relationships.

We evoked a feminist developmental lens to interpret themes which centralized males as physical and sexual aggressors and to offer culturally-relevant program and practice recommendations.
\end{abstract}

\section{Introduction}

The developmental importance of adolescent dating relationships is reflected through an increasing body of research (Collins, Welsh, \& Furman, 2009). Although positive dating experiences have been associated with increased self-esteem, academic achievement, and positive outlooks for future family cohesion (Moosmann \& Roosa, 2015), some adolescents experience sexual pressure and other forms of abuse within their first relationships. By common definition, teen dating violence (TDV) includes perpetration and/or victimization of physical, emotional, threatening, relational, and/or sexual harm within a dyadic intimate context (Wolfe et al., 2001), and is a global public health problem (Connolly et al., 2010; Rivera-Rivera, Allen-Leigh, RodríguezOrtega, Chávez-Ayala, \& Lazcano-Ponce, 2007). Despite the widespread and growing recognition of this issue, there are a paucity of studies examining the meaning and contexts of TDV outside of the United States, and specifically in Mexico. This study will explore Mexican adolescents' perceptions of dating relationships, specifically attending to their perceptions of what they consider to be healthy versus unhealthy characteristics of romantic partnerships. We utilize a feminist developmental lens to interpret descriptions of males as aggressors of physical and sexual violence.

\subsection{Teen dating violence in Mexico}

Although representative samples are limited, research in Mexico suggests that adolescents are experiencing high rates of dating violence. The 2007 National Survey on Dating Violence found that $76 \%$ of youth ages 15-24 had experienced psychological TDV at least once in their lifetime. Within the past year, between 7 and $25 \%$ of adolescents had experienced physical violence (Instituto Mexicano de la Juventud, 2007). At odds with U.S.-based studies and perhaps attributable to measuring and reporting differences, rates of physical violence victimization tend to be lower for females (approximately 3-10\%) than males (approximately 10-23\%; Instituto Mexicano de la Juventud, 2007; Rivera-Rivera et al., 2007). These rates may be compared to $8.0 \%$ of romantically-involved youth in the U.S. (9\% of Hispanic females, $6 \%$ of Hispanic males) who had been physically victimized within the past year. In adolescence, victims of psychological and physical abuse are often also perpetrators and vice versa (Exner-Cortens, Eckenrode, \& Rothman, 2013). Sexual violence is a unique and particularly severe form of violence, although we were unable to ascertain rates concerning this type of abuse among youth in Mexico. In the United States, an average of $7 \%$ of youth between 9 th and 12 th grade had been victims of sexual violence by a dating partner within the past year (Centers for Disease Control and Prevention [CDC], 2018). For Hispanic females, this rate was nearly double that of the general population; nearly $12 \%$ of Hispanic females had been sexually perpetrated against, which may be compared to approximately 3\% of Hispanic males (CDC, 2018).

Adolescent romantic relationships are shaped by culture and context. The experience of TDV is more likely among youth living within poverty-stricken areas of Mexico (Instituto Mexicano de la Juventud,

\footnotetext{
* Corresponding author.

E-mail addresses: Heidi.Rueda@utsa.edu (H.A. Rueda), steven_hoffman@byu.edu (S. Hoffman).
} 
2007). Youth's exposure to multiple forms of violence, including parental intimate partner violence (IPV) and violence within their communities also predicts their own use of violence (Brady, Gorman-Smith, Henry, \& Tolan, 2008). This is particularly concerning given the high rates of IPV among married women with children in Mexico (ENVIM, 2009). Adolescents who witness violence across environmental contexts are more likely to suffer from anxiety, depression, and to utilize violence themselves (Mrug \& Windle, 2010). They are also at greater proclivity to accept dating violence, which has been associated with perpetrating physical and sexual dating violence (see Vagi et al., 2013 for a review). Despite calls for primary prevention with Hispanic youth (Haglund et al., 2018; Malhotra, Guarda-Gonzalez, \& Mitchell, 2014), school-aged youth in Mexico have limited exposure to TDV interventions (Sosa-Rubi, Saavedra-Avendano, Piras, Van Buren, \& BautistaArredondo, 2016).

Adolescents' dating relationships are also shaped by gendered expectations, which are developmentally and culturally influenced (author citation, 2015). Within Mexican cultural norms, femininity is often characterized by proscriptions to maintain relational harmony, to place a man's desires above her own, and to remain sexually pure and faithful (i.e., marianismo; Castillo, Perez, Castillo, \& Ghosheh, 2010). On the contrary, masculinity discourses tend to emphasize an acceptance of early sexual behaviors and virility within relationships (Villarruel, Jemmott, Jemmott, \& Ronis, 2007). Mexican masculinity (i.e., machismo) has further been associated with negative traits inclusive of dominance, assertiveness, and desire for control (Gonzalez-Guarda, Ortega, Vasquez, \& De Santis, 2010), although it is noteworthy that these have received more attention in the literature than positive aspects (e.g., emotional attentiveness, leadership; Arciniega, Anderson, Tovar-Blank, \& Tracey, 2008; Pardo, Weisfeld, Hill, \& Slatcher, 2012). Raffaelli and Ontai (2001) describe a societal double-standard where Latino parents restrict or discourage adolescent females from engaging in romantic relationships because they are concerned about them dating young men who demonstrate negative masculine traits. This double-standard was evidenced in a recent study among MexicanAmerican girls in a U.S. border state who felt as though it was easier for boys to get away with certain behaviors such as cheating on their girlfriends (author citation, 2014a). Similarly, sexual pressure is a primary concern for Mexican American girls in dating relationships (author citation, 2014b).

Cultural norms and local environments also intersect to impact dating decisions such as timing (Espinosa-Hernández, Vasilenko, \& Bámaca-Colbert, 2016), partnership length, and partner selection (Tyrell, Wheeler, Gonzales, Dumka, \& Millsap, 2016). Few studies speak to how Mexican youth make these dating decisions, although research does suggest that parents often restrict their daughters from dating until their quincienera (age 15) or until they have left the house (Raffaelli \& Ontai, 2001). When dating does begin, the introduction of a partner to one's parents can denote a particularly salient transition whereby the partner is integrated into their family life (author citation, 2013). Sexual activity and timing are societally influenced by the Catholic religion, which may serve as protective and can also attenuate risk. For example, one study of adolescents in Mexico found that youth who valued virginity were less likely to be sexually active. However, this same study found that high school girls were particularly susceptible to experiencing internalized sexual guilt (Espinosa-Hernández et al., 2016).

\subsection{Feminist developmental framework}

Given the highly salient role of gendered cultural norms in Hispanic adolescents' experiences with dating, we evoke a feminist developmental framework (see Impett, Schooler, \& Tolman, 2006). This perspective centralizes romantic and sexual experiences as highly influencial in adolescent identity development, and to female adolescents in particular (Impett et al., 2006; Tolman, 2002). It underscores the patriarchal contexts that shape these experiences and, in doing so, draws from a myriad of feminist theories. Patriarchal contexts are particularly evidenced within Mexican culture where traditional gender roles exert pronounced influence (Ahrens, Rios-Mandel, Isas, \& del, 2010; Raffaelli \& Ontai, 2001; Updegraff, Umana-Taylor, McHale, Wheeler, \& Perez-Brena, 2012). Thus, in exploring adolescents' expectations and norms for dating relationships, we contextualize and interpret findings within societal, familial, and peer messages that promote male desire. Impett et al. (2006) describe how, stemming from these contexts, females can experience pressure to please their partners, inhibit authentic feelings, and succumb to sexual activity that is undesired. Both males and females can lose status by not behaving in alignment with these norms, although qualitative studies with Mexican American youth have found that girls are particularly challenged by a concomitant expectation for sexual relations and rumors that negatively impact their reputation when they are sexually active (author citation, 2013).

\subsection{Current study}

The aims of this research were a) to explore adolescents' perceptions of healthy and unhealthy relationships, including the gendered contexts that influence expectations and norms and b.) to compare their perceptions by gender and age. We sampled middle adolescents since these youth are just beginning to date, engage in sexual activity, and forge beliefs about relationships that are predictive of later quality of life (Espinosa-Hernández et al., 2016). We hope to address an important gap in research concerning how Mexican adolescents think about the health of dating relationships from a culturally and developmentally informed standpoint. Findings may leverage the effective design of relationship health programs and policies targeting Mexican-heritage youth.

\section{Material and methods}

\subsection{Sample}

Upon approval from the governing Institutional Review Board to conduct this project and its procedures, adolescents from a rural area of Michoacán, Mexico participated in a study on adolescent health and romantic relationships. As part of this study, youth in their 1st, 2nd, and 3rd (U.S. equivalent $=7$ th -9 th grade) years of middle school participated in surveys $(N=112)$ and gender-divided focus groups (11 to 14 participants each; $N=98$ ) that took place during the school day. Participants were recruited by a collaborating Mexican research team trained in the study's methods and research questions. The team was comprised of one male and one female school psychologist who were trained via skype by the first and second authors. Passive parental consent was utilized by the school, and youth verbally assented to their participation. The original decision to use active and written consent was decided against by the Mexican research team because migrating to the U.S. is a large part of the daily life of the community and a main source of income for families. Asking families to divulge their names was felt to be unethical and disallowing of youth participation. Instead, the research team met with parents and youth and personally answered questions that individuals had including risks and benefits to participation and discussion of confidentiality. Three females and fifteen males opted to not participate.

Prior to focus groups, students were given a survey consisting of questions about their dating lives and including about dating violence perpetration and victimization. Although the primary aim of this study was to understand youth's voiced perspectives, we also include this information (Table 1) to contextualize qualitative themes. Focus groups were led by the school psychologists and consisted of five male $(n=61)$ and three female $(n=37)$ groups. Each was led by a same-gender moderator. See Table 2 for sample demographics. Focus group 
Table 1

Relationship characteristics of study participants $(N=112)$.

\begin{tabular}{|c|c|c|c|c|}
\hline & $N$ & Frequency & M & (SD) \\
\hline Ever Dated & 65 & $58.0 \%$ & & \\
\hline Age Started Dating & & & 11.65 & $(1.54)$ \\
\hline Average Number of Partners & & & 3.31 & $(2.81)$ \\
\hline Heterosexual & 103 & $92.0 \%$ & & \\
\hline \multicolumn{5}{|l|}{ Current Relationship Status } \\
\hline Going-out & 26 & $29.5 \%$ & & \\
\hline Single & 57 & $64.8 \%$ & & \\
\hline Other & 5 & $5.7 \%$ & & \\
\hline \multicolumn{5}{|c|}{ Currently Dating an Older Partner } \\
\hline Males & & $5.3 \%$ & & \\
\hline Females & & $36.5 \%$ & & \\
\hline \multicolumn{5}{|l|}{ Ever Had Sexual Intercourse } \\
\hline Yes & & $5.4 \%$ & & \\
\hline No & & $94.6 \%$ & & \\
\hline \multicolumn{5}{|l|}{ Past 12 Months } \\
\hline \multicolumn{5}{|c|}{ Perpetrated Any Physical Violence } \\
\hline Males & 7 & $15.6 \%$ & & \\
\hline Females & 6 & $19.4 \%$ & & \\
\hline \multicolumn{5}{|c|}{ Victim of Any Physical Violence } \\
\hline Males & 7 & $15.6 \%$ & & \\
\hline Females & 2 & $6.5 \%$ & & \\
\hline \multicolumn{5}{|l|}{ Perpetrated Any Sexual Violence } \\
\hline Males & 6 & $13.6 \%$ & & \\
\hline Females & 1 & $3.2 \%$ & & \\
\hline \multicolumn{5}{|l|}{ Victim of Any Sexual Violence } \\
\hline Males & 7 & $16.3 \%$ & & \\
\hline Females & 1 & $3.2 \%$ & & \\
\hline \multicolumn{5}{|c|}{ Perpetrated Any Emotional Violence } \\
\hline Males & 13 & $26.5 \%$ & & \\
\hline Females & 13 & $40.6 \%$ & & \\
\hline \multicolumn{5}{|c|}{ Victim of Any Emotional Violence } \\
\hline Males & 15 & $31.3 \%$ & & \\
\hline Females & 12 & $38.7 \%$ & & \\
\hline
\end{tabular}

Note. Some youth participated in the survey and not the focus groups, resulting in a slightly larger sample size of surveyed participants $(52.30 \%$ male). A relationship status of "other" denotes that the adolescent was in a casual dating relationship. Valid percentages were used when there was missing data. Violence indicators denote that the adolescent had enacted or had been victim to violence at least one time by a dating partner in the past year (Conflict in Adolescent Dating Relationships Inventory-SF; Fernández-González, Wekerle, \& Goldstein, 2012).

Table 2

Descriptive information of focus group participants $(\mathrm{N}=98)$.

\begin{tabular}{llll}
\hline & $N$ & Frequency & M \\
\hline Sex & & & \\
Male & 61 & $62.2 \%$ & \\
Female & 37 & $37.8 \%$ & \\
Males & & & \\
Grade Levels & & & \\
1st & 11 & & \\
2nd & $36^{\mathrm{a}}$ & & \\
3rd & 14 & & \\
Females & & & \\
Grade Levels & & & \\
1st & 11 & & \\
2nd & 12 & & \\
3rd & 14 & & \\
Age & & & \\
12 & 12 & $12.3 \%$ & \\
13 & 30 & $30.6 \%$ & \\
14 & 24 & $24.5 \%$ & \\
15 & 20 & $20.4 \%$ & \\
16 & 8 & $8.2 \%$ & \\
17 & 4 & $4.1 \%$ & \\
\hline
\end{tabular}

Note. Grade levels are equivalent to United States 7th, 8th, and 9th grades.

a One focus group was conducted for each grade level per sex, with the exception of three focus groups conducted with 2nd grade males. moderators were given key questions with probes as a means to make direct comparisons across groups. Key questions included, "What are some characteristics of a healthy relationship?", "Describe an ideal dating relationship.", "What are some qualities that indicate that a relationship is unhealthy or abusive?", "What are some things that can happen in a relationship that some people think is alright but others may think is unhealthy or abusive?"

\subsection{Analysis}

Data from the focus groups included audio-taped recordings and verbatim transcripts, which were translated from Spanish to English by the Mexican researchers and a bilingual graduate research assistant. We used a qualitative analysis software program (NVIVO; QSR International Pty Ltd., 2014 Version 10) to manage data, and analyzed the content via inductive thematic analysis. A graduate research assistant (third author) first open coded the transcripts, noting salient patterns and devising a preliminary codebook (Creswell, 2007). Together with a second researcher (first author), the codebook then underwent multiple reiterations until both researchers determined that the themes and subthemes meaningfully conveyed the data. A third and independent researcher utilized the codebook to assess inter-rater reliability, which was excellent ( $\alpha=0.91)$. We also conducted a member check of findings (Padgett, 2008), meaning that the two Mexican research psychologists on our international team offered feedback to contextualize, ensure accurate translation, and offer culturally-salient implications. Finally, we calculated frequencies by theme, subtheme, age, and sex and display these in Table 3. Although focus groups were divided by grade level, students of various ages were present in each group. In describing results, "younger adolescents" pertains to those participants aged 12 to 14 and "older adolescents" pertains to those aged 15 to 17 years. Consistent with typical ages of middle schoolers in Mexico, there was a greater proportion of 12-14 year olds (66 of 98), and many of the 15-17 year olds were aged 15 ( 20 of 32 ; see Table 1 ). Quotations from participants are utilized to demonstrate key themes, using aliases assigned by youth themselves during groups.

\section{Results}

In discussing relationships, youth described both their own and their friends' early dating experiences and the qualities that they desired of a romantic partnership in the future. Although questioned about both healthy and unhealthy relationship qualities, youth focused to a greater extent on what they feared or did not want from a relationship. Traditional and gendered cultural norms were strongly evident in adolescents' dialogue, including themes of control and dominance, female sexual virtue and self-silencing, and males as perpetrators of physical and sexual aggression. Themes are presented in the order in which the youth discussed them (i.e., first healthy relationships, second unhealthy) and subthemes are presented in order of salience.

\subsection{Healthy relationships}

In general, youth desired several positive traits from their partners including that they be loving, honest, and respectful. Youth also tended to focus heavily on what they did not want of a relationship despite being probed about healthy relationship qualities. Specifically, youth felt that girls should not manipulate, lecture, or order around their partners, that boys should not sexually grope, and that the relationship should be free of violence. We outline these subthemes in detail.

\subsection{1. "That we respect each other"}

When asked to describe characteristics of healthy relationships, the most outstanding theme across female and male focus groups was that youth desired mutuality. Although a number of positive relationship 
Table 3

Frequency count of coded data across themes and subthemes $(n=336)$.

\begin{tabular}{|c|c|c|c|c|c|}
\hline & Total n(\%) & Age (12-14 years) & Age (15-17 years) & Male & Female \\
\hline \multicolumn{6}{|c|}{ Healthy Relationships $(n=115,34.2 \%)$} \\
\hline Reciprocity & $50(43.5 \%)$ & $35(30.4 \%)$ & $15(13.0 \%)$ & $26(22.6 \%)$ & $24(20.9 \%)$ \\
\hline Respect/Good Communication & $26(22.6 \%)$ & $19(16.5 \%)$ & $7(6.1 \%)$ & $13(11.3 \%)$ & $13(11.3 \%)$ \\
\hline Free of violence & $22(19.1 \%)$ & $17(14.8 \%)$ & $5(4.3 \%)$ & $12(10.4 \%)$ & $10(8.7 \%)$ \\
\hline Pleasing sexual experiences & $10(8.7 \%)$ & $6(5.2 \%)$ & $4(3.5 \%)$ & $9(7.8 \%)$ & $1(0.9 \%)$ \\
\hline Not controlled by a partner & $7(6.1 \%)$ & $5(4.3 \%)$ & $2(1.7 \%)$ & $6(5.2 \%)$ & $1(0.9 \%)$ \\
\hline Total & $115(100 \%)$ & $82(71.3 \%)$ & $33(28.7 \%)$ & $66(57.4 \%)$ & $49(42.6 \%)$ \\
\hline \multicolumn{6}{|c|}{ Unhealthy Relationships ( $n=221,65.8 \%$ ) } \\
\hline Peer Involved Jealousy & $79(35.8 \%)$ & $61(27.6 \%)$ & $18(8.1 \%)$ & $37(16.7 \%)$ & $42(19.0 \%)$ \\
\hline Violence & $54(24.4 \%)$ & $47(21.3 \%)$ & $7(3.2 \%)$ & $26(11.8 \%)$ & $28(12.7 \%)$ \\
\hline Proof of Love & $48(21.7 \%)$ & $37(16.7 \%)$ & $11(5.0 \%)$ & $27(12.2 \%)$ & $21(9.5 \%)$ \\
\hline Being Ordered Around & $40(18.1 \%)$ & $38(17.2 \%)$ & $2(0.9 \%)$ & $21(9.5 \%)$ & $19(8.6 \%)$ \\
\hline
\end{tabular}

Note: Frequencies refer to the number of responses in each category, not the number of respondents

qualities were upheld, these were explicitly contextualized by the role that both partners played in sustaining a healthy bond, "That they [ $a$ relationship partner] take into account the opinion of both partners.” (Axel, 13 yo male, 2nd year). Traditional gendered roles were commonly evidenced, including male power in decision-making, "That we respect each other. That he respects us and we respect his decisions." (Diana, 13 yo female, 1st year). This notion of female responsibility was reflected by some males' dialogue as well, "That if they want us to respect them, they respect themselves too." (Pancracio, 15 yo male, 2nd year).

Females in particular discussed the desire of being "faithful to one another" (Emily, 15 yo female, 2nd year) with some references to them being responsible for this quality in a relationship, "Like if you get along kindly with him, be faithful, tell him the truths that happen and such" (Mixary, 13 yo female, 1st year). Females were also more apt than males to desire complete openness and reciprocity in sharing what may otherwise be considered private details of their personal life, "Tell each other our secrets so that we don't have any secrets, and know everything." (Rosita, 13 yo female, 1st year). This notion of "knowing everything" was further emphasized by Victoria (12 yo female, 1st year), "That you know your boyfriend's life and he knows your life." (Victoria, 12 yo female, 1st year). Learning about one another was discussed more generally by others as an opportunity to build friendship (e.g., "To get to know each other...like an experience." Shakira, 16 yo female, 3rd year) and learning to communicate, "Be sincere...by saying that you do not understand what he is saying or he should ask you to clarify when he does not understand you. Speak with clarity." Mayte, 12 yo female, 1st year).

Older adolescents embedded general positive characteristics within discussion of mutuality; younger adolescents, however, tended to state these as stand-alone descriptors. They felt that healthy relationships should contain "trust", "honesty", "respect", "appreciation", "sincerity", and that it is important "that they are happy." The notion of loving and respecting females was evident from multiple youth, "Well everyone has their own point of view...like...for me he would be honest, loving respectful of me." (Jazmin, 14 yo female, 2nd year). Males referenced using words of affirmation, "Because you have to respect the woman....you give her love...you tell her beautiful things, that you care for her." (Axel, 12 yo male, 1st year).

\subsection{2. "Free of violence"}

Dialogue across both male and female groups emphasized the desire to not resort to violence, and some stated that they would not allow themselves to remain in a relationship that could become physically abusive, “... that if he wants to hit me, not to let him... that at the moment he wants to hit me or something or wants to lay his hand on me, to leave him..." (Rosita, 13 yo female, 1st year). One male also described a way in which to help a friend resolve conflict using positive communication strategies, "Tell them...to talk with her and to resolve things with words, not to resolve the conflict with hitting." (Steven, 17 yo male, 3rd year). Further elaborating on the notion of healthy communication, some youth felt that a healthy relationship should not contain verbal argument (e.g., "Without fighting" Miko, 14 yo male, 2nd year; La Directioner, 15 yo female, 2nd year), while others characterized certain forms of verbal or emotional behaviors as unhealthy ("Do not insult her"Axel, 12 yo male, 2nd year; "Not to let yourself be manipulated..." Isabela, 14 yo female, 2 nd year).

\subsection{3. "They don't grope"}

Adolescent males of various ages described sexual behavior, one explicitly mentioning "That they have sex" (Sanders, 14 yo male, 2nd year), and another expressing "That they have children" (Naruto, 15 yo male, 3rd year) as healthy and desirable within relationships. Another older male described the importance of contraceptive use, "Using contraceptives in a relationship is healthy. You prevent yourself from illnesses..." (Panfilo, 16 yo male, 3rd year). Male dialogue reflected that couples should not show public displays of affection, "That there is no groping" (Ron, 13 yo male, 2nd year). Bart (13 yo male, 2nd year) contexualized this rule as stemming from females, "Well...for example, a young girl...is...sincere, she would not want you be, like kissing, fondling... that is what she does not like, she wants you all to be discreet." Only one female (16 years old) discussed having sex as part of a healthy relationship, "Sex...when both individuals want to..." (Shakira, 16 yo female, 3rd year). This conversation then turned to discussion among the girls of how undesired or forced sex constitutes violence.

\subsection{4. "Does not order me around"}

A final subtheme emerged from some younger and older adolescent males whereby female power over a male was viewed as unhealthy. This included, "not being ordered around" (Sanders, 14 yo male, 2nd year), "not being manipulated," (Pancracio, 15 yo male, 2nd year) and "not being lectured"(Jerry, 13 yo male, 2nd year). Following advice to not let a woman manipulate, Stefen (13 yo male, 2nd year) described how males should also be careful not to let a girlfriend control how they interact with other females including that they be allowed to "...greet friends who are girls" noting that it should be alright to, "greet them with a kiss." Another younger male expressed that a girl should consider herself his equal, "That she does not boast a lot, that she thinks herself the same." (Juancho, 14 yo male, 2nd year). One counterexample was offered by a female who gave advice to others in her group to, "Not let yourself be manipulated, be hit, or be prohibited from things." (Isabela, 14 yo female, 2nd year).

\subsection{Unhealthy relationships}

When probed to discuss unhealthy relationships, youth perceptions of these included jealousy, which was fueled by peer involvement on social media sites, partner violence, females having to prove their love through sexual behavior, and males being ordered around by their girlfriends. Youth commonly utilized gender pronouns depicting males 
as both physical and sexual aggressors. Females, like males, were apt to become jealous although suffered more severe consequences to their reputations when rumors resulted from their other-sex interactions.

\subsection{1. "When there is jealousy"}

Across all groups, although more prevalent among younger adolescents, youth provided descriptions of relational conflict stemming from jealousy. Jealousy was spurred by cheating, which sometimes included just talking to the other sex. Youth also described a lack of trust in the other which was fueled by social media. Acting out of jealousy, youth gossiped and hurt one another's reputations. Although these trends were prominent among both males and females, the processes and examples given varied. Multiple males described situations where a female would see them with another female and become jealous, "...you get along with her [a girl who is a friend] and... the old lady sees you and... that is when the jealousy starts." (Jeimy, 15 yo male, 3rd year). Jeimy went on to describe that his girlfriend controlled him by not wanting him to "talk to people who she says are not good for you." Halo's (13 yo male, 2nd year) example was similar, "That they see you with other people and get angry," although Chema (14 yo male, 2nd year) discussed jealousy stemming from overt cheating. In context, her example referred to the potential for cheating at parties while using drugs or alcohol, "Or they have sexual relations with another person in front of their partner [under the influence]."

When females displayed any type of sexual behavior, they risked male jealousy and gossip, "Before anything even happens, guys are not going to take you seriously because they say 'ah she lets herself be groped,' 'ay, she likes that you do this to her,' 'talk to her beautifully and then you take her and done." (Mixary, 13 yo female, 1st year). Natalia (12 yo female, 1st year) also explained that females were subject to sexual critique and males telling their friends about private sexual aspects of their relationship, "And then they go criticizing everything and they tell everything that you all did to their friends." Females further highlighted jealousy stemming from social media websites:

You have your Facebook and you have a lot of friends...and you have your cousins there and...you love him [your cousin] a lot and just like that your boyfriend thinks that he is your boyfriend. He gets jealous... (Natalia, 12 yo female, 1st year)

Some described that their boyfriend would attempt to set boundaries around their social media contacts and posts:

That if you upload a photo there and someone comments saying 'How pretty' or something like that, they will ask you 'Who is he to you?' and you say that he is your friend and he tells you a friend would not post that..."

(Isabela, 14 yo female, 2nd year)

\subsection{2. "That a man wants to hit the woman"}

Younger adolescents across both genders emphasized the tendency to view physical violence as unhealthy. Physical violence perpetration was viewed by both males and females as primarily male-initiated, whether stated overtly (e.g., "That they only want to abuse the woman." Jimmy, 12 yo male, 1 st year) or identified via pronoun use (“...he would hit her." Axel, 13 yo male, 2nd year; "He will start to pull you." Isabela, 14 yo female, 2nd year; "He grabs her or handles her." Lolis, 16 yo female, 3rd year).

Females provided greater detail in their discussion of violence dynamics, whether through personal stories or using examples from adults. Multiple females felt that a males were violent towards women because "he loves her.... when they say that they love you and they mistreat you...one day my boyfriend hit me and he says 'I do all this for you because I love you.'” (Rosita, 13 yo female, 1st year). Youth felt that females were unlikely to leave an abusive partnership. However, one female provided an idea about how a physically abusive relationships could come to an end:
Or when the people are already married, the husband hits her and says: 'I do this because I love you' and sincerely...says 'it is the last time that this will happen' and he keeps on until the woman... gets tired and denounces him. (Milagros, 13 yo female, 1st year).

\subsection{3. "Or when they ask you for the proof of love"}

Although not as readily recognized as a type of violence, males and females both felt that sexual pressure from males was common. Describing an unhealthy aspect of relationships, Messi (15 yo male, 3rd year) stated, "When the girlfriend does not want sex." Male dialogue in particular highlighted examples of rape, "Or including at parties, how should I say this? The man he wants... to do something to the woman and... gets her drunk and takes advantage of her." (Bart, 13 yo male, 2nd year). Similarly, Gordito (14 yo male, 2nd year) described, "When the men want to have sexual relations and the women do not and they obligate them to."

Females discussed how they often felt pressured to engage in sexual behaviors "...to demonstrate that you love him" (Lena, 14 yo female, 2nd year), or to demonstrate trust, "Or when they ask you to undress or something like that and then they tell you that if you don't do it you have no trust..." Chaparrita (14 yo female, 2nd year). They feared rejection and threats of what might happen if they did not engage sexually, as described by Mayte (12 yo female, 1st year), “...if you do not give me a proof of love, I don't want to be anything to you." It followed that many felt sexually objectified, "When they order you and they want to give you kisses and you think 'he does not love me because of me, he loves me because of my body." (Victoria, 12 yo female, 1st year). Further, females described a double standard where engaging in sexual behaviors could mean ultimate rejection and reputational damage:

Like also sometimes the boys can do...a bet with friends and they want to see...how far you can go and then you decide how far you want to go because if you have sexual relations with them... they will leave you, because they are going to say that you are going to let yourself be groped by all the boys.

(Diana, 13 yo female, 1st year)

\subsection{4. "That they want you to always do what he says"}

Mirroring their earlier discussion within the context of healthy relationship dialogue, both males and females returned to the importance of not being controlled or ordered around as they discussed unhealthy relationship dynamics. Younger adolescent boys in particular gave examples of adult males controlling a wife's whereabouts and holding her accountable to household duties, "like the guy will not let his wife go anywhere...because... [he is] like a womanizer while he has a wife locked up at home." (Chema, 12 yo male, 1st year). "It is bad because...the guy can go out and the woman is only kept locked up doing chores." (Axel, 12 yo male, 1st year). Compared to males, females' dialogue tended to reflect control issues in their current relationships, "That you don't dress a certain way." (Lena, 14 yo female, 2nd year). Females withdrew from activities, both out of fear of their boyfriend being upset (e.g., "They leave things that are important because it bothers their boyfriend." (Isabella, 14 yo female, 2nd year) and of him leaving the relationship, "...you do what he asks you to do so that he stays with you and never leaves you." (Mayte, 12 yo female, 1st year). Females described a resulting loss of dignity, "I mean he is taking care of me, I don't feel ownership of myself..." (Diana, 13 yo female, 1st year). This notion of losing oneself to a male was described by Victoria (12 yo female, 1st year) as an act of selfsilencing and sacrifice, "Often, many when they love him will say, 'It is okay- for you I will do everything' and many [girls] do sacrifice themselves and say 'you ask me for something, I will give it..."'.

\section{Discussion}

The aims of this study were to explore the perceptions of Mexican 
youth concerning healthy and unhealthy qualities within romantic relationships as well as to offer comparisons by age and gender. Although we have learned more about dating among Mexican American youth in recent years, a lack of voiced experiences from Mexican youth has left a void with regard to understanding this population within their own right. Incorporating Mexican youth viewpoints is essential to the design of dating health services and programs abroad and in the United States. Use of a feminist developmental theory is helpful in interpreting results, particularly as themes centralized male power and desire.

Youth enumerated a number of positive qualities that they desired of a relationship, inclusive of reciprocity/mutuality, respect, and good communication. Some dialogue reflected that it was a female's role to adhere to a male's decisions and to be a faithful partner, aligning with traditional gender role socialization, specifically that positing marianismo as the counterpart to machismo within Hispanic culture adherence (Castillo et al., 2010; Gonzalez-Guarda et al., 2010). Adolescents' emphasis on mutuality is particularly noteworthy, however, as some research with Mexican adolescents has suggested that beliefs in mutuality may protect youth against dating violence (Espinoza, Hokoda, Ulloa, Ulibarri, \& Castañeda, 2012; Ulloa, Jaycox, Marshall, \& Collins, 2004). Also similar to other research with Mexican American youth (Tyrell et al., 2016), girls conveyed greater attention to emotional closeness as important to a healthy relationship. Their wanting to understand the intimate details of their partners' lives may also reflect fear of cheating. In alignment, males noted sexual gratification as an important component of a healthy relationship while females' voices were notably absent to this regard.

A central theme pertaining to youth's descriptions of unhealthy relationships centered on difficulty pertaining to peer-involved jealousy and cheating. In keeping with a feminist developmental lens, these concerns may be interpreted within a heteronormative and patriarchal societal discourse. Females feared sexual infidelity on behalf of their male partners, reflecting prior research associating male popularity with a number of sexual partnerships and finding the reverse for females (Kreager \& Staff, 2009). Reflecting U.S.-based research of Mexican American youth, "cheating" behaviors were thought to include a range of interactions with the other-sex whether in person (e.g., hugging, talking) or online (e.g., liking a picture; author citation, 2014a; author citation, 2014b). Females feared reputational damage via rumors that easily stereotyped them as sexually promiscuous, which were fueled by social media. Developmentally, jealousy by both sexes may be considered normative and commonly spur anger and arguments between youth couples (Giordano, Copp, Longmore, \& Manning, 2015). Jealousy, however, is also a risk factor for verbal/emotional violence perpetration (Hokoda, Martin Del Campo, \& Ulloa, 2012), as are traditional cultural scripts (Santana, Raj, Decker, La Marche, \& Silverman, 2006) particularly when overly rigid (author citation, 2014a). What was lacking from data in this study were thick descriptions of the processes by which jealousy became an unhealthy aspect of relationships, whereas rich descriptions among Mexican American youth have provided detailed accounts of both cognitive (e.g., acceptance of violence, male possessiveness) and behavioral (e.g., verbal argument) components contributing to relationship distress for certain couples and not others (author citation, 2014a). Further research is required with Mexican youth samples.

Youth's conceptualizations of unhealthy relationships depicted males as perpetrators of physical dating violence and male youth also spoke of females as perpetrators of emotional violence (i.e., control, manipulation). Interestingly, however, youth's self-reported emotional and physical violence rates suggest that females were acting as more frequent perpetrators of both these forms of violence. Of adolescent couples who utilize violent conflict strategies, bidirectionality is common (Messinger, Fry, Rickert, Catallozzi, \& Davidson, 2014; 76\% Latina sample). However, we were unable to assess the contexts of violent episodes. Whereas most violence between youth is low in control and constitutes minor acts of aggression, qualitative accounts from youth in our study mirror a subtype of violence described as female resistance to male heightened control (Messinger et al., 2014). Our findings call attention to the importance of how youth are conceptualizing gender roles within a societal discourse where negative forms of machismo may be idealized. Where male control is priviledged, females may be enacting less severe forms of violence in selfdefense or "resistance" to relationship dynamics that render them less power (Messinger et al., 2014).

Although sexual violence is often studied alongside other forms of violence, it is a particularly severe form of dating violence and girls dating boys who are older than them are at heightened risk (Kennedy, Bybee, McCauley, \& Prock, 2018). This type of dating context is common within Latino culture (Tyrell et al., 2016), and was experienced by youth in our study. Specifically, $36.50 \%$ of females compared to $5.30 \%$ of males were dating an older partner. Adolescent girls in our study described having to "prove their love" through sexual behavior. We sampled youth who had just begun dating during early to midadolescence, a majority of whom had been in a relationship (58.04\%) but not yet had sexual intercourse $(94.60 \%)$. It is noteworthy that despite not having had sex, nearly one-quarter of both boys and girls reported being victimized by sexual violence (i.e., forced intercourse, or being sexually touched against their will; Fernández-González et al., 2012). It may be that boys were relunctant to discuss sexual acts of aggression amidst other boys. Future research should ask more nuanced questions of boys regarding sexual violence, perhaps via individual interviews. In this study, older females offered the most detailed and personal examples of sexual contexts, which they described as maledominated and accompanied by manipulation (i.e., sex as love) and threats (i.e., to leave). Females may be blamed or silenced for instances of sexual abuse (Ahrens et al., 2010), particularly within cultural norms that priviledge males, value female chastity, and aim to preserve family reputation (Castillo et al., 2010).

\subsection{Implications}

Contextually, youth lived in an area marked by high levels of crime and our Mexican collaborators on the study reported that many youth held migratory aspirations to move to the United States. In designing dating violence prevention programs both in the United States and abroad for Hispanic youth populations, it will remain imperative to include content related to gender role expectations and acceptance of dating violence (Malhotra et al., 2014). Understanding the values that shape young Mexican adolescents' intimate relationships is important for effective programming efforts on both sides of the border. Sexual discussion is made more or less likely and varies in context by reliosity, socioeconomic status, acculturation, and degree of family closeness (Gutierrez-Serrano, Chagolla, \& Romo, 2018). Parents should be included in sexual health education efforts, one such program being the "Families Talking Together" created by the Center for Latino Adolescent and Family Health (Guilamo-Ramos et al., 2011).

Finally, it is noteworthy that some younger adolescents in our study drew from adult models (e.g. parents, cousins, Spanish television programs) in describing healthy and unhealthy relationship attributes. Although we studied youth's qualitative perceptions, quantitative measurements of traditional gender roles tend to utilize adult verbage (e.g. "Men should share housework with their wives"; Neff, 2001) suggesting that these may be most appropriate for younger adolescents for whom relationship dynamics are largely conceptualized by adults in their lives. However, this may also suggest that youth who are dating ( $58 \%$ of our sample) are beginning to draw from their own experiences and new measurement tools which reflect adolescent dating language are needed.

\subsection{Limitations}

This collaborative study offered an underserved population with 
less power in society the opportunity to voice their experiences in a confidential space among peers (Umaña-Taylor \& Bámaca, 2004). It was cross-sectional and findings are limited, however, in their transferability to other Mexican youth populations since we sampled middle schoolers from one rural school in Central Mexico. Our collaborators in Mexico reported that some youth's decision not to participate may have been because they held migratory aspirations and others had relatives in the U.S. already. These youth may have feared involvement in a U.S.based study given politics surrounding migration. Further, our data offered only preliminary explorations. Future mixed methods research should continue to explore types of conflict situations that may elicit violence, gender socialization within Mexican families and peer groups, and resistance among females to societal messages pertaining to their sexuality.

\section{Conclusion}

Gender norms are often a target of research for Hispanic youth populations, and youth in our study evoked dichotomized and traditional gendered perspectives suggesting that these continue to be highly salient at least for certain populations of Mexican youth. Much of youth dialogue when asked about both healthy and unhealthy relationship characteristics revolved around what they feared or did not desire. We suggest TDV prevention efforts be multi-tiered through inclusion of parents, schools, and counselors to help youth to think critically about how cultural discourses around sexuality and dating can serve to promote or hinder healthy relationships. Young adolescence is a critical time to forge positive schemas for relationships, inclusive of adaptive forms of masculinity and femininity. To the contrary, youth who develop unhealthy ideals may be susceptible to sexual shame, self-silencing, and deferred help-seeking.

\section{Declaration of Competing Interests}

None.

\section{Acknowledgements}

We would like to express our profound gratitude to our international research team in Central Mexico. Their assistance with obtaining consent, facilitating focus groups, translation, and providing member feedback was much appreciated. They have and continue to be essential to this research.

These individuals and their respective organizations are not responsible for the quality or accuracy of the present manuscript, which is the sole responsibility of the authors. Nor do they necessarily agree with any or all of the report's findings and recommendations.

\section{References}

Ahrens, C. E., Rios-Mandel, L., Isas, L., \& Del, C. L. (2010). Talking about interpersonal violence: Cultural influences on Latinas 'latinas' identification and disclosure of sexual assault and intimate partner violence. Psychological Trauma: Theory, Research, Practice, and Policy, 2, 284-295.

Arciniega, G. M., Anderson, T. C., Tovar-Blank, Z. G., \& Tracey, T. J. G. (2008). Toward a fuller conception of machismo: Development of a traditional machismo and caballerismo scale. Journal of Counseling Psychology, 55, 19-33.

Brady, S. S., Gorman-Smith, D., Henry, D. B., \& Tolan, P. H. (2008). Adaptive coping reduces the impact of community violence exposure on violent behavior among African American and Latino male adolescents. Journal of Abnormal Child Psychology, 36, 105-115.

Castillo, L. G., Perez, F. V., Castillo, R., \& Ghosheh, M. R. (2010). Construction and initial validation of the marianismo beliefs scale. Counseling Psychology Quarterly, 23, 163-175.

Centers for Disease Control and Prevention (2018). Youth Risk Behavior Surveillance-United States, 2017. Retrieved from https://www.cdc.gov/ healthyyouth/data/yrbs/pdf/2017/ss6708.pdf.

Collins, W. A., Welsh, D. P., \& Furman, W. (2009). Adolescent romantic relationships. Annual Review of Psychology, 60, 631-652. https://doi.org/10.1146/annurev.psych. 60.110707.163459.
Connolly, J., Nocentini, A., Menesini, E., Pepler, D., Craig, W., \& Williams, T. S. (2010). Adolescent dating aggression in Canada and Italy: A cross-national comparison. International Journal of Behavioral Development, 34, 98-105.

Creswell, J. W. (2007). Qualitative inquiry and research design: Choosing among five approaches (2nd ed.). Thousand Oaks, CA: Sage.

ENVIM (2009). Encuesta Nacional Sobre Violencia Contra Las Mujeres. Retrieved from http://cedoc.inmujeres.gob.mx/documentos_download/ENVIM_2006.pdf.

Espinosa-Hernández, G., Vasilenko, S. A., \& Bámaca-Colbert, M. Y. (2016). Sexual behaviors in Mexico: The role of values and gender across adolescence. Journal of Research on Adolescence, 26, 603-609.

Espinoza, G., Hokoda, A., Ulloa, E., Ulibarri, M., \& Castañeda, D. (2012). Gender differences in the relations among patriarchal beliefs, parenting, and teen relationship violence in Mexican adolescents. Journal of Aggression, Maltreatment \& Trauma, 21, 721-738.

Exner-Cortens, D., Eckenrode, J., \& Rothman, E. (2013). Longitudinal associations between teen dating violence victimization and adverse health outcomes. Pediatrics, 31, $71-79$.

Fernández-González, L., Wekerle, C., \& Goldstein, A. L. (2012). Measuring adolescent dating violence: Development of 'conflict in adolescent dating relationships inventory'short form. Advances in Mental Health, 11, 35-54.

Giordano, P. C., Copp, J. E., Longmore, M. A., \& Manning, W. D. (2015). Contested domains, verbal "amplifiers," and intimate partner violence in young adulthood. Social Forces, 94, 923-951.

Gonzalez-Guarda, R. M., Ortega, J., Vasquez, E. P., \& De Santis, J. (2010). La mancha negra: Substance abuse, violence, and sexual risks among Hispanic males. Western Journal of Nursing Research, 32, 128-148.

Guilamo-Ramos, V., Bouris, A., Jaccard, J., Gonzalez, B., Mccoy, W., \& Aranda, D. (2011). A parent-based intervention to reduce sexual risk behavior in early adolescence: Building alliances between physicians, social workers, and parents. Journal of Adolescent Health, 48, 159-163.

Gutierrez-Serrano, G., Chagolla, D., \& Romo, L. (2018). Latina mother-daughter communication: Determinants of themes in conversations about dating and sexuality. Poster presented at the Bienniel Conference of the Society for Research on Adolescence, Minneapolis, MN.

Haglund, K., Belknap, R. A., Edwards, L. M., Tassara, M., Hoven, J. V., \& Woda, A. (2018). The influence of masculinity on male Latino adolescents' perceptions regarding dating relationships and dating violence. Violence Against Women, 25(9), 1039-1052 1077801218808395.

Hokoda, A., Martin Del Campo, M., \& Ulloa, E. (2012). Age and gender differences in teen relationship violence. Journal of Agression, Maltreatment \& Trauma, 21, 351-364.

Impett, E. A., Schooler, D., \& Tolman, D. L. (2006). To be seen and not heard: Femininity ideology and adolescent girls' sexual health. Archives of Sexual Behavior, 35, 131-144.

Instituto Mexicano de la Juventud (2007). Encuesta Nacional de Violencia en las Relaciones de Noviazgo 2007. Retrieved from http://www.imjuventud.gob.mx/ imgs/uploads/ENVINOV_2007__Resultados_Generales_2008.pdf.

Kennedy, A. C., Bybee, D., McCauley, H. L., \& Prock, K. A. (2018). Young women's intimate partner violence victimization patterns across multiple relationships. Psychology of Women Quarterly, 42(4), 430-444 10361684318795880.

Kreager, D. A., \& Staff, J (2009). The sexual double standard and adolescent peer acceptance. Social Psychology Quarterly, 72, 143-164.

Malhotra, K., Guarda-Gonzalez, R. M., \& Mitchell, E. M. (2014). A review of teen dating violence prevention research: What about Hispanic youth? Trauma, Violence, \& Abuse, 16, 444-4651524838014537903.

Messinger, A. M., Fry, D. A., Rickert, V. I., Catallozzi, M., \& Davidson, L. L. (2014). Extending Johnson's intimate partner violence typology: Lessons from an adolescent sample. Violence Against Women, 20, 948-971.

Moosmann, D. A., \& Roosa, M. W. (2015). Exploring Mexican American adolescent romantic relationship profiles and adjustment. Journal of Adolescence, 43, 181-192. https://doi.org/10.1016/j.adolescence.2015.06.004.

Mrug, S., \& Windle, M. (2010). Prospective effects of violence exposure across multiple contexts on early adolescents' internalizing and externalizing problems. Journal of Child Psychology and Psychiatry, 51, 953-961.

Neff, J. A. (2001). A confirmatory factor analysis of a measure of "machismo" among Anglo, African American, and Mexican American male drinkers. Hispanic Journal of Behavioral Sciences, 23, 171-188.

Padgett, D. K. (2008). Qualitative methods in social work research. Thousand Oaks, CA: Sage.

Pardo, Y., Weisfeld, C., Hill, E., \& Slatcher, R. B. (2012). Machismo and marital satisfaction in Mexican American couples. Journal of Cross-Cultural Psychology, 44 299-315.

QSR International Pty Ltd (2014). NVivo 10 [Computer software]. Retrieved from http:// www.qsrinternational.com.

Raffaelli, M., \& Ontai, L. L. (2001). 'She's 16 years old and there's boys calling over to the house': An exploratory study of sexual socialization in Latino families. Culture, Health \& Sexuality, 3, 295-310.

Rivera-Rivera, L., Allen-Leigh, B., Rodríguez-Ortega, G., Chávez-Ayala, R., \& LazcanoPonce, E. (2007). Prevalence and correlates of adolescent dating violence: Baseline study of a cohort of 7960 male and female Mexican public school students. Preventive Medicine, 44, 477-484. https://doi.org/10.1016/j.ypmed.2007.02.020.

Santana, M., Raj, A., Decker, M., La Marche, A., \& Silverman, J. (2006). Masculine gender roles associated with increased sexual risk and intimate partner violence perpetration among young adult men. Journal of Urban Health, 83, 575-585.

Sosa-Rubi, S. G., Saavedra-Avendano, B., Piras, C., Van Buren, S. J., \& BautistaArredondo, S. (2016). True love: Effectiveness of a school-based program to reduce dating violence among adolescents in Mexico City. Prevention Science, 18, 804-817.

Tolman, D. L. (2002). Dilemmas of desire: Teenage girls talk about sexuality. Cambridge, MA: 
Harvard University Press.

Tyrell, F. A., Wheeler, L. A., Gonzales, N. A., Dumka, L., \& Millsap, R. (2016). Family influences on Mexican American adolescents' romantic relationships: Moderation by gender and culture. Journal of Research on Adolescence, 26, 142-158.

Ulloa, E., Jaycox, L., Marshall, G., \& Collins, R. (2004). Acculturation, gender stereotypes, and attitudes about dating violence among Latino youth. Violence and Victims, 19, 273-287.

Umaña-Taylor, A. J., \& Bámaca, M. Y. (2004). Conducting focus groups with Latino populations: Lessons from the field. Family Relations, 53, 261-272.

Updegraff, K. A., Umana-Taylor, A., McHale, S. M., Wheeler, L. A., \& Perez-Brena, N. J. (2012). Mexican-origin youth's cultural orientations and adjustment: Changes from early to late adolescence. Child Development, 83, 1655-1671.

Vagi, K. J., Rothman, E. F., Latzman, N. E., Tharp, A. T., Hall, D. M., \& Breiding, M. J. (2013). Beyond correlates: A review of risk and protective factors for adolescent dating violence perpetration. Journal of Youth and Adolescence, 42, 633-649.

Villarruel, A. M., Jemmott, J. B., Jemmott, L. S., \& Ronis, D. L. (2007). Predicting condom use among sexually experienced Latino adolescents. Western Journal of Nursing Research, 29, 724-738. https://doi.org/10.1177/0193945907303102.

Wolfe, D. A., Scott, K., Reitzel-Jaffe, D., Wekerle, C., Grasley, C., \& Straatman, A. L. (2001). Development and validation of the conflict in adolescent dating relationships inventory. Psychological Assessment, 13, 277. 